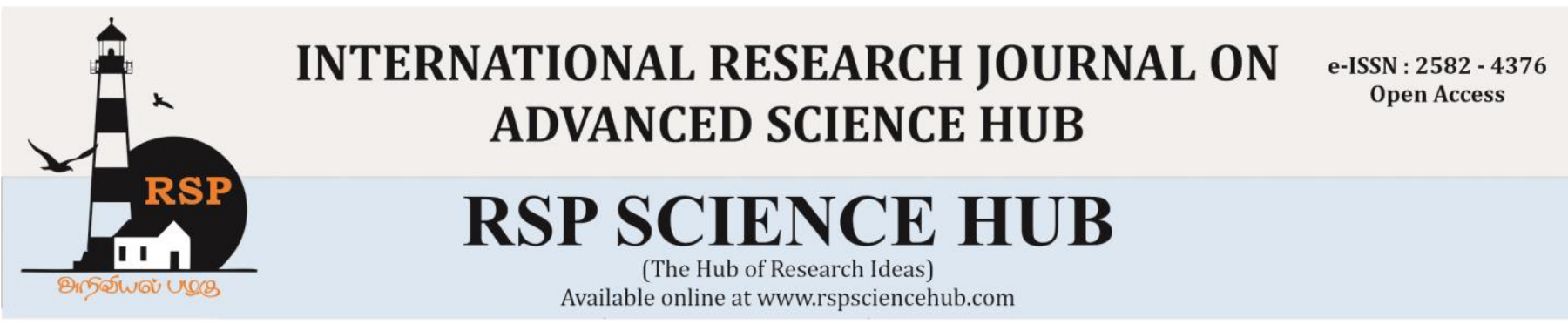

\title{
Current Control Mode Based Analysis of Grid Connected PV System
}

Sindhuja $D^{1}$, Dr. V. Prasanna Moorthy ${ }^{2}$

${ }^{1} P G$ Scholar, Department of Electrical and Electronics Engineering, Government College of Technology, Coimbatore - 641013, Tamilnadu, India

${ }^{2}$ Associate Professor, Department of Electrical and Electronics Engineering, Government College of Technology, Coimbatore - 641013, Tamilnadu, India

sindhu.dharmaraja@gmail.com ${ }^{1}$

Abstract

Renewable based power generation is rising rapidly due to high energy demand and carbon issues. Partial shading effect of the PV system leads to a significant reduction of the energy yield and quantity of reduction is depending on the geometry of shading effect. The incremental conductance and integral controller are used in this paper to display the maximum power point in the PV device. During bad weather conditions, insulated PV systems do not have enough power to supply the consumer. The key suggestions of this paper are to use the deficient power needed for the PV system through grid and to fed the PV system surplus power to the grid. The new control mode is used to monitor the PV current that uses two control loops for feedback. The current mode control system is a scheme for regulating electronic DCDC power converters. On a PV system using MATLAB/SIMULINK a complete model of $100 K W$ grid connected solar photovoltaic system using current mode controlled two-level three-phase VSC.

Keywords: (PV system, Maximum Power Point Tracking MPPT), Partial Shading Condition (PSC), VSC(Voltage Source Converter, Grid)

\section{Introduction}

The use of renewable-based power generation reduced high demand and carbon problems. Renewable energy is one of the alternatives for burning fossil fuels without carbon dioxide emissions, no pollution. Solar is the main source of renewables for electricity generation. In PV system it depends on temperature, level of irradiance, and generation of power reduced by partial shading conditions. The PV system was created at a multiple peak point, under partial shading conditions. The point can lower power generation at these multiple peaks. Partial shading of the PV system results in power generation reduction and quantity depends on the geometry of shading artifacts. In the presence of partial shading and mismatch impedance, bypass diodes cannot provide complete elimination of excessive power dissipation due to cell reverse biasing, typically referred to as hot-spotting in photovoltaic systems. High performance STMPPT technique based on ACMC to monitor the true peak of PV device under PSC. The current mode controller of the proposed technique has a very strong transient response for a disruption of input and output [1]. In the PV plane, the MPPT algorithm uses a trapezoidal area which contains all possible GMPPs for any PSC to reduce the voltage range to be tracked. Preventing energy losses due to PSC that in tradition MPPT techniques can reach 25 percent, being faster than other efficient GMPPT algorithms and preventing losses that can exceed 0.5 percent of energy generation per year [2]. 
Due to its complex monitoring capability, the GMPPT control technique, the $\mathrm{P} \& \mathrm{O}$ algorithm is used under uniform irradiance conditions, and the MPP voltage and current are continuously monitored. When partial shading is detected, the FWA is used to determine the GMPP, owing to its good exploration and exploitation characteristics, and fast convergence [3].

\subsection{Grid Connected PV system}

A $100 \mathrm{KW} \mathrm{PV}$ array is connected to a $25 \mathrm{KV}$ grid via a DC-DC boost converter and a 3 phase-3 level Voltage Source Converter (VSC). Maximum Power Point Tracking (MPPT) is implemented using the 'Incremental Conductance and Integral Regulator' technique in the boost converter, using a Simulink model. PV array delivering a maximum of $100 \mathrm{KW}$ at $1000 \mathrm{~W} / \mathrm{M}^{2}$ sun irradiance. $5 \mathrm{KHZ}$ DC-DC boost converter from natural PV voltage (273V DC at full power) to $500 \mathrm{~V}$ DC rising voltage. A MPPT controller which uses the 'Incremental Conductance and Integral Regulator' technique optimizes the switching duty cycle. This MPPT system automatically varies the duty cycle in order to produce the necessary voltage to extract full power. Two control loops are used by the VSC control system: an external control loop that regulates DV link voltage to $+/-250 \mathrm{~V}$ and an internal control loop that regulates $\mathrm{I}_{\mathrm{d}}$ and $\mathrm{I}_{\mathrm{q}}$ grid currents (active and reactive current components). $I_{d}$ current reference is the external controller output of the DC voltage. To preserve unity power factor, the existing reference $I_{q}$ is set to zero. The current controller's $\mathrm{V}_{\mathrm{d}}$ and $\mathrm{Vq}$ voltage outputs are translated to three modulating Vabc reference signals used by the PWM generator. The control system uses a 100-microsecond sample time for voltage and current controllers as well as for the PLL synchronizing unit. [4-7] Boost and VSC pulse generators use a fast sample time of 1 microsecond to get suitable resolution of PWM waveforms. $10 \mathrm{KVAR}$ condenser bank filtering VSC-made harmonics. Three-phase coupling transformer $100 \mathrm{KVA} 260 \mathrm{~V} / 25 \mathrm{KV}$, Utility grid (25KV distribution feeder and $120 \mathrm{KV}$ equivalent transmission system).

The photovoltaic array uses 330 SunPower modules. The array consists of 66 strings
$(66 * 5 * 305.2 \mathrm{~W}=100.7 \mathrm{KW})$ of 5 series connected modules connected in parallel. A signal builder block which is connected to the input of the PV array determines the irradiance and temperature profiles.[8-10]

\subsection{I-V \& P-V characteristics of Various Irradiance and Temperature}

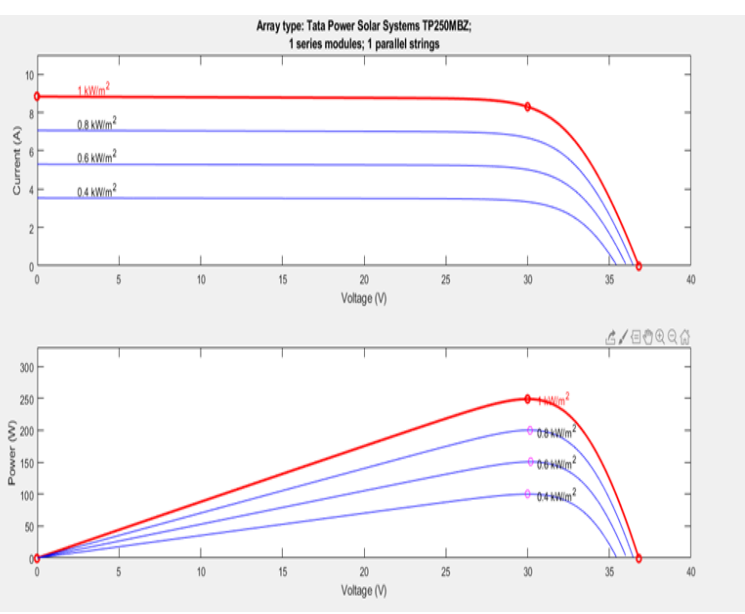

Fig 1: I-V \& P-V characteristics of varies irradiance

As shown in Figure 1 the I-V characteristics of typical solar panel. When the voltage and current characteristics $\mathrm{P}-\mathrm{V}$ is obtained as shown in Figure 2. The point indicated as MPP is the maximum panel output power.

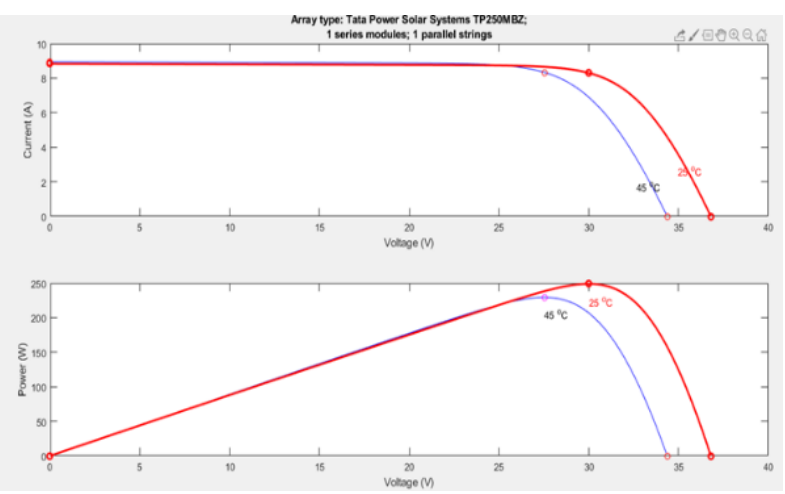

Fig 2: I-V \& P-V characteristics of varies temperature.

\section{MPPT Technique}

Incremental Conductance and Integral Regulator

Incremental conductance is one of the essential strategies in this method and because of its higher Steady-state precision and environmental 
adaptability it is a commonly applied tracked monitoring strategy. Incremental Conductance method operates on the basis that the slope at MPP is equal to zero on the P-V curve, it is positive on the left side of the MPP, and negative on the right side, equation. It can be seen that the P-V curve can be divided into three regions, represented by the set of equations. The change in MPP voltage can be determined by comparing the increase in power versus the increase in voltage between two consecutive samples.

- Slope $=0$ (MPP is reached)

- Slope $<0$ (at the right of MPP)

- Slope $>0$ (at the left of MPP)

By using derivative then: Slope $=(\mathrm{dP} / \mathrm{dV})=(\mathrm{d}(\mathrm{IV}) /(\mathrm{dV}))=\mathrm{I}+\mathrm{V}(\Delta \mathrm{I} / \Delta \mathrm{V})$ $=(\mathrm{I} / \mathrm{V})+(\Delta \mathrm{I} / \Delta \mathrm{V})$

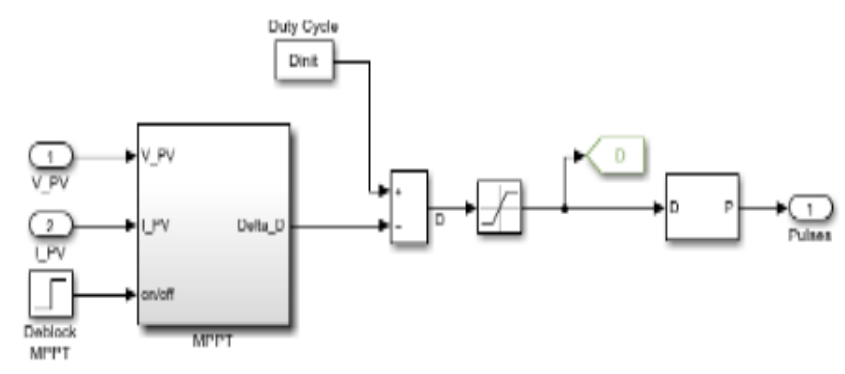

Fig 3: Incremental Conductance \& Integral controller Algorithm

\section{Three phase VSC model}

The key task of the three-phase VSC (inverter) in this model is to transform the boost converter DC output power into AC power which is ideal for connecting to the utility grid. The gating signals are produced using the technique of sinusoidal pulse width modulation (SPWM) by comparing a modulating sinusoidal signal. Generated by the VSC closed-loop control system with a highswitching, triangular carrier wave [4].

The control loops of the VSC are implemented in order to keep the active and reactive power generated from it and to transmit to the utility grid. Depending on the current control mode or the voltage control mode [5] this controller may be done. Given the easy implementation of the voltage control mode, it has little power over the current VSC line and no defense against current problems. However, complicated the current mode control, it has some features such as high output accuracy, protection against $\mathrm{AC}$ side voltage and load variations [6]. AC signals have to be converted from abc-frame to dq-frame using the Clark transformation matrix [7] below

$\left[\begin{array}{l}d \\ q \\ o\end{array}\right]=\frac{2}{3}\left[\begin{array}{ccc}\cos \theta & \cos \left(\theta-\frac{2 \pi}{3}\right) & \cos \left(\theta+\frac{2 \pi}{3}\right) \\ \sin \theta & \sin \left(\theta-\frac{2 \pi}{3}\right) & \sin \left(\theta+\frac{2 \pi}{3}\right) \\ \frac{1}{2} & \frac{1}{2} & \frac{1}{2}\end{array}\right]\left[\begin{array}{l}a_{1} \\ b \\ C\end{array}\right]$

The control loop consists of the following components:

\subsection{PHASE-LOCKED LOOP}

The transition from the abc-frame to the dqframe involves synchronization between the abc values and the dq values, thus incorporating the phase-locked loop (PLL) block into the method. It essentially consists of oscillator voltage control (VCO), output signal limiter and compensator. The transformation angle generated (axis in radians) from the PLL and the AC voltage dq values.

\subsection{Reference Signal Generator}

Its main function is to match the real and reactive power generated by the system with its required values and also to produce the current reference values in dq-frame (idref), (iqref) according to the following equations:

$$
\begin{aligned}
& i_{\text {dref }}=\left(2 / 3 V_{d}\right) P_{\text {ref }} \\
& i_{\text {qref }}=\left(-2 / 3 V_{d}\right) Q_{\text {ref }}
\end{aligned}
$$

\section{Simulation Results}

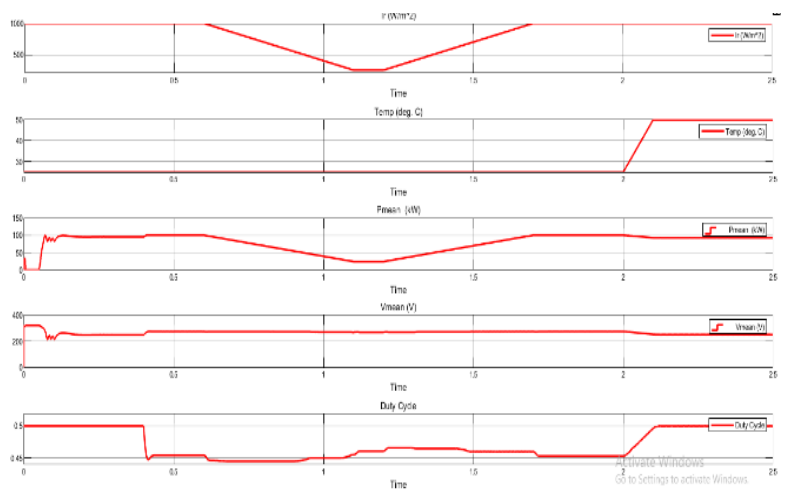

Fig 4 : Waveform of PV irradiance, Temperature, Power, Voltage, Duty cycle

Simulation begins with normal test conditions ( 25 deg.C, $1000 \mathrm{~W} / \mathrm{M}^{2}$ ). Pulses to boost, and VSC converters are blocked from $\mathrm{t}=0 \mathrm{sec}$ to $\mathrm{t}=0.05 \mathrm{sec}$. $\mathrm{PV}$ voltage is the voltage of the open circuit 


\section{www.rspsciencehub.com}

(Nseries $*$ Voc $=5 * 64.2=321 \mathrm{~V}$, Vmean trace on PV scope).

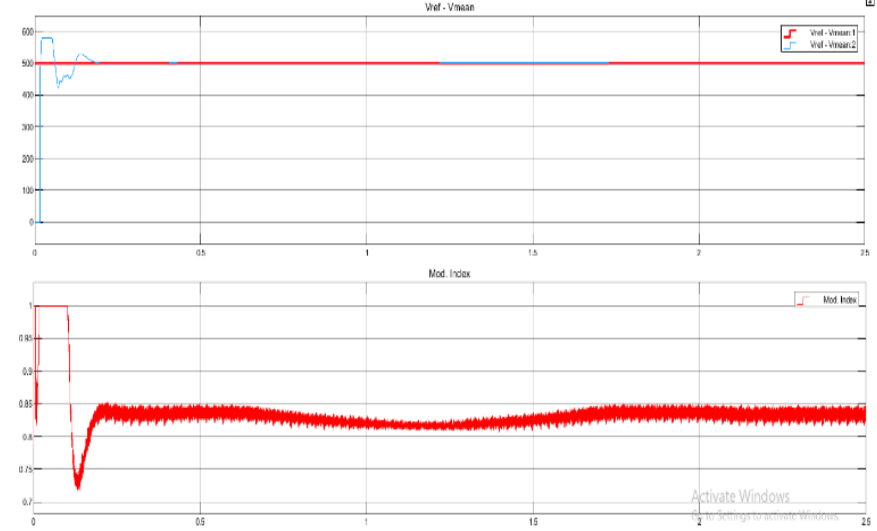

Fig 5: Waveform of Vref - Vmean

Boost and VSC converters get deblocked at $\mathrm{t}=0.05$ sec. The voltage for the DC connection is set at $\mathrm{Vdc}=500 \mathrm{~V}$.

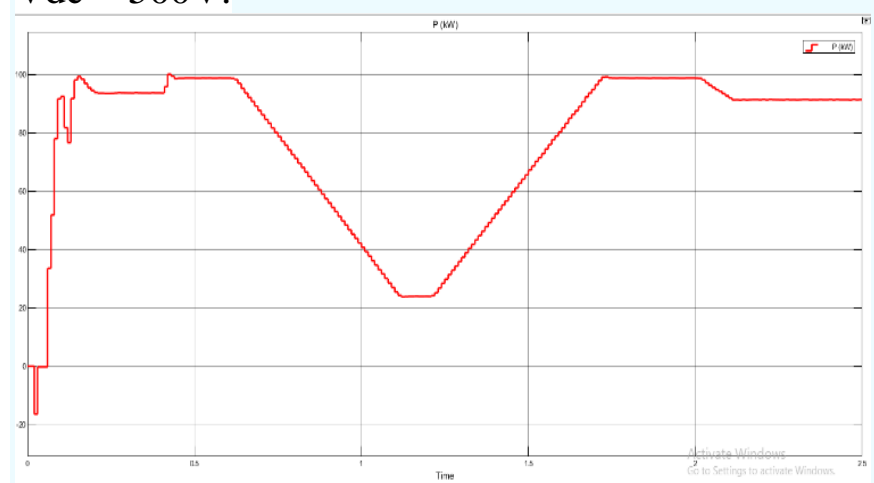

Fig 6: Output Waveform of Grid Power

It reaches a steady state at $t=0.25$ sec. Consequently, resulting PV voltage is $\mathrm{V} \mathrm{pv}=(1-$ D) * Vdc. The output power of the PV array is 96 $\mathrm{KW}$ whilst the maximum power specified is 100.7 KW.

At $t=0.4 \mathrm{sec}$ MPPT regulates the start of PV voltage regulation by varying duty cycle to extract the maximum power. Maximum power is obtained at $100.4 \mathrm{KW}$ if the duty cycle is $\mathrm{D}=0.454$. Sun irradiance is ramped down from $1000 \mathrm{~W} / \mathrm{M}^{2}$ to $250 \mathrm{~W} / \mathrm{M}^{2}$ from $\mathrm{t}=0.6 \mathrm{sec}$ to $\mathrm{t}=1.1 \mathrm{sec}$. MPPT is continuing to track maximum production. When irradiance has decreased to $250 \mathrm{~W} / \mathrm{M}^{2}$, at $\mathrm{t}=1.2 \mathrm{sec}$, the service period is $\mathrm{D}=0.461$. Vmean $=268 \mathrm{~V}$ and Pmean $=24.3 \mathrm{KW}$ correspond to $\mathrm{PV}$ voltage and power. From $\mathrm{t}=1.2 \mathrm{sec}$ to $\mathrm{t}=2.5 \mathrm{sec}$ Sun irradiance is restored back to $1000 \mathrm{~W} / \mathrm{M}^{2}$ and then temperature increased to 50 deg.c to measure the effect of temperature rising. As the temperature increases
Volume 02 Issue 06 June 2020

from 25 deg.c to 50 deg.c the output power of the array decreases from $100.7 \mathrm{KW}$ to $93 \mathrm{KW}$.

\section{Conclusions}

The paper proposes a MPPT technique based on current mode controller to monitor the maximum power of a PV device under PSC. The current mode controller of the proposed technique has a very good transient response to disturbances in input and output. Grid-connected PV system was designed and researched using MATLAB/SIMULINK with current control mode to dominate the actual and reactive power transmitted from the grid VSC.

\section{References}

\section{Journals}

[1] Seyedkazem Hosseini, Student Member, IEEE, Shamsodin Taheri, Member, IEEE, Masoud Farzaneh, Life Fellow, IEEE and Hamed Taheri "A High Performance Shade - Tolerant MPPT Based on Current Mode Controller," IEEE Trans. On Power Electronics.

[2] A. M. S. Furtado, F. Bradaschia, M. C. Cavalcanti, and L. R. Limongi, "A reduced voltage range global maximum power point tracking algorithm for photovoltaic systems under partial shading conditions," IEEE Trans. Ind. Electron., vol. 65, no. 4, pp. 3252-3262, Apr. 2018.

[3] C. Manickam, G. P. Raman, G. R. Raman, S. I. Ganesan, and N. Chilakapati, "Fireworks enriched $\mathrm{P} \& \mathrm{O}$ algorithm for GMPPT and detection of partial shading in PV systems," IEEE Trans. Power Electron., vol. 32, no. 6, pp. 4432-4443, Jun. 2017.

[4] M. H. Rashid, Power electronics handbook: Butterworth-Heinemann, (2017).

[5] A. Yazdani and R. Iravani, Voltagesourced converters in power systems: modeling, control, and applications: John Wiley \& Sons, (2010). 
[6] . M. P. Kazmierkowski and L. Malesani, "Current control techniques for three-phase voltage-source PWM converters: A survey," IEEE transactions on industrial electronics, vol. 45, pp. 691-703. H. S. Nalwa, Editor, "Magnetic Nanostructures", American Scientific Publishers, Los Angeles,(2003).

[7] P. Klause, O. Wesynczuk, and S. Sudhoff, "Analysis of Electric Machinary and Drive System," John Willey and Sons, Inc. Publication, (2002).

[8] K. L. Lian, J. H. Jhang, and I. S. Tian, "A maximum power point tracking method based on perturb-and-observe combined with particle swarm optimization," IEEE J. Photovoltaics, vol. 4, no. 2, pp. 626-633, Mar. 2014.

[9] L. L. Jiang, D. R. Nayanasiri, D. L. Maskell, and D. M. Vilathgamuwa, "A hybrid maximum power point tracking for partially shaded photovoltaic systems in the tropics," Renew. Energy, vol. 76, pp. 5376, 2015.

[10] L. Nguyen and K. S. Low, "A global maximum power point tracking scheme employing DIRECT search algorithm for photovoltaic systems," IEEE Trans. Ind. Electron., vol. 57, no. 10, pp. 3456-3467, Oct. 2010. 